www.jmscr.igmpublication.org

Index Copernicus Value: 79.54

ISSN (e)-2347-176x ISSN (p) 2455-0450

crossref DOI: https://dx.doi.org/10.18535/jmscr/v7i5.43

Journal Of Medical Science And Clinical Research

IGM Publication

An Official Publication of IGM Publication

$\underline{\text { Research Paper }}$

\title{
A Comparative Study to Assess Clinical Outcome with or without receiving Antibiotics in Patients during Post Operative Period in Clean Elective Surgeries
}

\author{
Authors \\ Dr Nitin Kumar ${ }^{1}$, Dr Samir Gupta (MS,M.Ch.) ${ }^{2}$, Dr Prashant Raj Pipariya (MS) ${ }^{3^{*}}$ \\ ${ }^{1}$ Post graduate student, Department of Surgery, Gajra Raja Medical College, Gwalior \\ ${ }^{2}$ Associate Professor, Department of Surgery, Gajra Raja Medical College, Gwalior \\ ${ }^{3}$ Professor, Department of Surgery, Gajra Raja Medical College, Gwalior \\ Corresponding Author \\ Dr Prashant Raj Pipariya (MS) \\ Professor, Department of Surgery, Gajra Raja Medical College, Gwalior, MP, India
}

\begin{abstract}
Aims \& Objective: We used to afraid to avoid postoperative antibiotics in government hospitals due to variable factors. It is necessary to decrease the use of antibiotics to prevent development of antibiotic resistance and also to decrease the financial burden on patients. So we designed a study to define the role of prophylactic use of preoperative antibiotics in clean elective surgical cases.

Methods: We conducted a prospective, randomized trial comparing wound infection rates in 100 patients (group A- 50 received preoperative $2 g$ ceftriaxone + postoperative antibiotics for 5-7 days, group B-50 received preoperative $2 g$ ceftriaxone only) undergoing clean elective surgical cases in Gajra Raja Medical College, Gwalior(MP). All the cases were followed up at 3rd postoperative day, at the time of discharge, $10^{\text {th }}$ postoperative day and after one month. These patients were analysed. Rate of different post-operative complications and duration of hospital stay were recorded. CDC criteria was used to define wound infection.

Result: Groups were well matched for all preoperative variables studied. The overall infection rate was $5 \%$ (5 out of 100). The incidence of wound infection in group A was 4\% and 6\% in group B, which was statistically insignificant. Also there was no statistically significant difference in hospital stay of patients (average hospital stay of group A patients is 2.39 days whereas in group B patients is 2.32 days).

Conclusion: Based on our results we do not recommend the routine use of post-operative antibiotic prophylaxis in clean elective case.
\end{abstract}

\section{Introduction}

Surgical site infections (SSI) are one of the most common causes of postoperative morbidity. Patients who experience SSI have twice the morbidity, are $60 \%$ more likely to spend time in an intensive care unit and are five times more likely to be readmitted to hospital than patients without SSI. The efficacy of prophylactic antibiotics has been demonstrated in both animal and clinical studies. It is estimated that $40-60 \%$ SSI are preventable with proper prophylactic antibiotics administration. ${ }^{1}$ 
In spite of discoveries of newer antibiotics, surgical wound infection still remains a threat due to secondary bacterial contamination and widespread use of prophylactic antibiotics that lead to emergence of multi-drug resistant bacteria. ${ }^{2}$ The basic surgical skills of postoperative precaution, pre-operative preparation, excellent surgical technique, fastidious wound care and post-operative management are corner-stones of infection prophylaxis. Surgical wounds are expected to heal within a predictable time depending on the type, wound, and extent of surgery. Clean, surgical wound usually primarily closed and would be expected to require minimal intervention to enable healing to progress naturally and quickly without complication in the surgical wound. Antibiotics for prolonged period may be harmful to both individual and hospital colony whether they are given as prophylaxis or for therapy. ${ }^{1}$

The administration of antibiotics is not intended to sterilize tissue but to act as an adjunct to decrease the intra-operative microbial load to a level which can be managed by host immune responses. The goal of antibiotics therapy is to achieve sufficient tissue level at the time of microbial contamination and the optimal agent should be long acting, inexpensive and have a low side effect profile.,

\section{Aims and Objectives}

The present study aimed to compare the effect of single dose versus multiple dose antibiotic prophylaxis in clean elective surgery with regard to Surgical Site Infection and to find any benefit in treating elective patients postoperatively with antibiotics.

\section{Methods}

This was a prospective, comparative, randomised study consisting of cases admitted to G.R. Medical College and J.A. Group of Hospital, Gwalior, Madhya Pradesh from January 2017May 2018. During this period, 100 cases were selected for our study who underwent clean elective surgery.
The patients were randomly allocated using computer generated numbers to two categories: Group A and Group B of 50 cases each.

Group A comprises patients who received inj. ceftriaxone 2 giv at the time of induction of anaesthesia then

1. Continue ceftriaxone postoperatively for 2 days, $1 \mathrm{~g}$ iv twice a day followed by oral tab.

Amoxycillin (500mg) plus clavulanic acid (125mg) for 5 days or

2. Amoxycillin $(500 \mathrm{mg})$ plus clavulanic acid(125mg) for 7 days.

Group B comprises patients who received a single dose of $2 \mathrm{~g}$ of inj. Ceftriaxone at the time of induction or 30 minutes before skin incision. They received no further antibiotics i.v or oral.

\section{Exclusion Criteria}

- All patients who do not give consent for study.

- Patients expected to have clean-contaminated, contaminated or dirty surgery.

- Patients undergoing emergency surgeries.

- Patients having co-morbid conditions for eg. diabetes, immunocompromised states etc.

\section{Methodology}

On admission to hospital, a detailed proforma was filled with details like the diagnosis, preoperative investigations and meticulous preoperative preparation. All patients were followed up to 30 days postoperatively. Within thirty minutes of the skin incision, both Group A and B patients received a two gram single dose of ceftriaxone intravenously in the operating room. Patients in the Group A were given inj. ceftriaxone 1g iv BD for 2 days then oral tab. Amoxycillin (500mg) plus clavulanic acid (125mg) for 5 days or Amoxycillin $(500 \mathrm{mg})$ plus clavulanic acid (125mg) for 7 days. The administration of postoperative antibiotics was done intravenously in the surgical ward. No more antibiotic were given in group $\mathrm{B}$ patients in the post-operative period. Prior to the skin incision for patients of 
either group, the skin preparation was done using the available antiseptic solution (s): savlon, methylated spirit and 10 percentpovidone iodine. After proper sterile draping the incision was made and the actual procedure was done. The operation was done according to the surgeon's usual technical routine without altering anything. Wounds were closed primarily. Wounds were inspected on 3rd postoperative day, at the time of discharge, $10^{\text {th }}$ postoperative day and after one month. Stitches were removed on $10^{\text {th }}$ postoperative day in outpatient department. Wounds were examined for erythema and discharge, if there was discharge then sent for culture and sensitivity and patient was treated promptly with empirical iv antibiotics initially and later as per culture and sensitivity report.

The cost of antibiotics was calculated as the minimum rates of generic drugs from local medical stores. All the data were entered in the proforma. The available results and outcome in both groups were analysed and then they were compared with the previous studies and final conclusion was drawn.

\section{Results}

The present study consists of 100 patients undergone clean elective surgery in G.R. Medical College, Gwalior from January 2017- March 2018, were randomly allocated equally into two groups- Group A and group B. The incidence of age varied between 18-60 year but maximum number of patients belonged to 18-30 year age group. Sex ratio in both the groups was comparable.

Table 1: Age wise distribution of patients

\begin{tabular}{|l|c|c|c|c|}
\hline \multirow{2}{*}{$\begin{array}{l}\text { Age } \\
\text { group }\end{array}$} & \multicolumn{2}{|c|}{ Patients in group A } & \multicolumn{2}{c|}{ Patients in group B } \\
\cline { 2 - 5 } & Number & Percentage & Number & Percentage \\
\hline $18-30$ & 24 & 48 & 16 & 32 \\
\hline $31-40$ & 15 & 30 & 15 & 30 \\
\hline $41-50$ & 04 & 8 & 10 & 20 \\
\hline $51-60$ & 07 & 14 & 09 & 18 \\
\hline
\end{tabular}

Table 2: Sex wise distribution of patients in both group

\begin{tabular}{|l|c|c|c|c|}
\hline \multirow{2}{*}{ Sex } & \multicolumn{2}{|c|}{ Patients In Group A } & \multicolumn{2}{c|}{ Patients In Group B } \\
\cline { 2 - 5 } & Number & Percentage & Number & Percentage \\
\hline Male & 34 & 68 & 31 & 62 \\
\hline Female & 16 & 32 & 19 & 38 \\
\hline Total & 50 & & 50 & \\
\hline
\end{tabular}

\section{Operations Included in Study}

Maximum patients in our study were of inguinal hernia, fibroadenoma, sebaceous cyst and hydrocele. These include $78 \%$ of cases in group A and $70 \%$ in group B as shown in table no. 3 .

Table 3: No. of different operations included in study

\begin{tabular}{|l|c|c|c|}
\hline Disease & Group A & Group B & Total \\
\hline Inguinal Hernia & 12 & 08 & 20 \\
\hline Fibroadenoma & 10 & 13 & 23 \\
\hline Sebaceous cyst & 10 & 10 & 20 \\
\hline Dermoid cyst & 02 & 02 & 04 \\
\hline Lipoma excision & 03 & 04 & 07 \\
\hline Hydrocele & 07 & 04 & 11 \\
\hline Phimosis & 02 & 04 & 06 \\
\hline Varicocele & 00 & 01 & 01 \\
\hline Pilonidal sinus & 01 & 00 & 01 \\
\hline Varicose vein & 03 & 04 & 07 \\
\hline
\end{tabular}

\section{Postoperative Fever}

Table 4 depicts that $40 \%$ patients and $36 \%$ patients in Group A and Group B respectively had postoperative fever. The results were not statistically significant ( $\mathrm{p}>0.05)$.

Table 4: Postoperative fever

\begin{tabular}{|c|c|c|c|c|c|}
\hline \multirow{2}{*}{$\begin{array}{lr}\text { Presence } & \text { or } \\
\text { absence of post } \\
\text { fever }\end{array}$} & \multicolumn{2}{|c|}{ Present } & \multicolumn{2}{|c|}{ Absent } & Chi sq. \\
\hline & $\mathbf{n}$ & $\%$ & $\mathbf{n}$ & $\%$ & \multirow[t]{3}{*}{0.1698} \\
\hline Group A & 20 & 40 & 30 & 60 & \\
\hline Group B & 18 & 36 & 32 & 64 & \\
\hline
\end{tabular}

\section{Postoperative WBC Count}

Group B had postoperative raised WBC count in $8 \%$ patients while Group A postoperative raised WBC count in $6 \%$ patients. There was no statistically significant difference observed between the two study group ( $>>0.05)$. (Table 5)

Table 5: Postoperative raise in WBC count

\begin{tabular}{|l|c|c|c|c|c|}
\hline \multirow{2}{*}{$\begin{array}{l}\text { WBC count } \\
\text { raise }\end{array}$} & \multicolumn{2}{|c|}{ Increase } & \multicolumn{2}{c|}{ Normal } & \multirow{2}{*}{$\begin{array}{c}\text { Chi sq. test } \\
\text { value }=\mathbf{0 . 1 5 3 6}\end{array}$} \\
\cline { 2 - 5 } Group A & $\mathbf{N}$ & $\mathbf{\%}$ & $\mathbf{N}$ & $\mathbf{\%}$ & \\
\hline Group B & 3 & 6 & 47 & 94 & \\
\hline
\end{tabular}




\section{Post OP Surgical Site Infection}

Group B had postoperative surgical site infection in $6 \%$ cases while Group A had postoperative surgical site infection in $4 \%$ cases. There was no statistically significant difference observed between the two group ( $p>0.05$ ).

Table 7: Postoperative SSI

\begin{tabular}{|l|c|c|c|c|c|}
\hline \multirow{2}{*}{ Post op SSI } & \multicolumn{2}{|c|}{ Present } & \multicolumn{2}{c|}{ Absent } & \multirow{2}{*}{$\begin{array}{c}\text { Chi sq. test } \\
\text { value-0.2105 }\end{array}$} \\
\cline { 2 - 5 } Group A & 2 & 4 & N & $\%$ & \\
\hline Group B & 3 & 6 & 47 & 94 & \\
\hline
\end{tabular}

$\mathrm{P}$ value $=0.646$

\section{Duration of Post OP Hospital Stay}

Post operative hospital stay among single dose and multiple dose antimicrobial were comparable in two groups. The average hospital stay of group A patients was 2.39 days whereas in group B patients was 2.32 days.

Table 6: Duration of post op hospital stay

\begin{tabular}{|l|c|c|c|c|}
\hline $\begin{array}{l}\text { Duration of post op } \\
\text { stay(days) }\end{array}$ & $\mathbf{0 - 2}$ & $\mathbf{3 - 6}$ & $\mathbf{> 6}$ & $\begin{array}{c}\text { Chisq. Test } \\
\text { value-0.3182 }\end{array}$ \\
\cline { 1 - 4 } Group A & 21 & 27 & 2 & \\
\cline { 1 - 4 } Group B & 19 & 28 & 3 & \\
\hline
\end{tabular}

$\mathrm{P}$ value $=0.8529$

\section{Discussion}

Surgical site infection is a well known thing. This has been documented since origin of surgery. Strict asepsis, meticulous surgical techniques, less handling of tissues and use of prophylactic antibiotics reduced the incidence of SSI. $^{5}$ Moreover postoperative antibiotic administration was not found to reduce infectious complication but could increase antibiotic resistance. ${ }^{6}$

1) In our study, male patients were more common with male: female ratio 1.8:1.

2) The average hospital stay of patient without SSI was 1.98 days as compared to patient with SSI was 9.0 days which is significantly higher. Similarly, there was 3-5 times increased antibiotic use in patients with SSI as compared to patients without SSI. Thus significantly increasing cost and hospital stay if patient gets surgical site infection.

3) The cost of care for patients with multiple dose antibiotics was nearly fivefold higher (around $79.50 \%$ higher) than that for surgical patients single dose antibiotics prophylaxis.

4) The present study is compared with that of the similar studies conducted in the past.

\begin{tabular}{|l|c|}
\hline Study & SSI Rate \% \\
\hline Cruse et al. $^{7}$ & $7 \%$ \\
\hline Anne et al. & $0.59 \%$ \\
\hline Muhammed Sharif et al. & $5.4 \%$ \\
\hline Present Study & $05 \%$ \\
\hline
\end{tabular}

All of the above studies support the result of the present study that single dose antibiotic prophylaxis is as good as multiple dose regime.

5) In our study out of 50 patients of single dose antimicrobial group 18(36\%) had postoperative fever and similarly out of 50 patients of multiple dose antimicrobial group 20(40\%) had postoperative fever. There were no significant difference in single dose and multiple dose group. All the patients which had SSI had complaint of fever but the reverse was not true.

6) The mean hospital stay in single dose group is equivalent to multiple dose group as $p$ Value is 0.86 , so it can be inferred that there was no significant difference in post operative hospital stay in both groups.

\section{Conclusion}

From our study we conclude that there is no statistical difference between single dose and multiple dose antimicrobial treatment in terms of surgical site infection and post-operative hospital stay in clean elective surgery but there is needless increased financial burden in multiple dose antimicrobial treatment.

\section{References}

1. Mangram AJ, Horan TC, Pearson MI, Silver LC, Jarvis. Guideline for prevention of surgical site infection, Centre for disease control and prevention (CDC) hospital infection and control practice advisory committee. Am J Infect Control.1999;27:97-134. 
2. Bernard HR, Cole WR. The prophylaxis of surgical infection: the effect of prophylactic antimicrobial drugs on the incidence ofinfection following potentially contaminated operations. Surgery; 1964;56:151-7.

3. Smaill F, HofmeyrGJ. Antibiotics prophylaxis for caesarean section. The Cochrane Database Sys Rev.2002;3: CD000933.

4. Smaill F, Hofmeyr GJ. Antibiotics prophylaxis for caesarean section. Oxford: The Cochrane Library; 2007.p.4.

5. Karlatti S, Havannavar IB. A comparative prospective study of preoperative antibiotic prophylaxis in the prevention of surgical site infections.IntSurg J. 2016;3:141-5.

6. Bangaru H, Gaiki VV, Reddy MV. Comparative study of single dose preoperative antibiotics versus both preoperative and postoperative antibiotics in laparoscopic appendicectomy for nonperforated appendicitis.IntSurg J. 2017;4:3092-6.

7. Cruse PJ, Foord R. The epidemiology of wound infection: a 10 year prospective study of 62,939 wounds. Surgical Clinics North America. 1980;60(1):27-40. 